\title{
North Atlantic Oscillation Response to Anomalous Indian Ocean SST in a Coupled GCM
}

\author{
JÜRGEN BADER \\ Institute of Geophysics and Meteorology, University of Cologne, Cologne, and Max Planck Institute for Meteorology, \\ Hamburg, Germany \\ MojiB LATIF \\ Leibniz-Institute for Marine Sciences, University of Kiel, Kiel, Germany
}

(Manuscript received 23 November 2004, in final form 4 April 2005)

ABSTRACT

\begin{abstract}
The dominant pattern of atmospheric variability in the North Atlantic sector is the North Atlantic Oscillation (NAO). Since the 1970s the NAO has been well characterized by a trend toward its positive phase. Recent atmospheric general circulation model studies have linked this trend to a progressive warming of the Indian Ocean. Unfortunately, a clear mechanism responsible for the change of the NAO could not be given. This study provides further details of the NAO response to Indian Ocean sea surface temperature (SST) anomalies. This is done by conducting experiments with a coupled ocean-atmosphere general circulation model (OAGCM). The authors develop a hypothesis of how the Indian Ocean impacts the NAO.
\end{abstract}

\section{Introduction}

The North Atlantic Oscillation (NAO) is a largescale alternation of atmospheric mass with centers of action near the Icelandic low and the Azorian high. It is the dominant pattern of atmospheric variability in the North Atlantic sector throughout the year, although it is most pronounced during winter and accounts for more than one-third of the interannual winter total variance in sea level pressure (Cayan 1992; Hurrell et al. 2003, and references therein). The NAO has shown strong interannual and decadal variability during the last century and has exhibited a strong upward trend since the 1970s and a reverse trend in the 1950s and 1960s (Hurrell 1995). Different hypotheses were put forward to explain the low-frequency changes of the NAO. Internal atmospheric dynamics were suggested by James and James (1989). Saravanan and McWilliams (1997) linked the low-frequency variability to a stochastic forcing by the atmosphere driving low-frequency

Corresponding author address: Jürgen Bader, Max Planck Institute for Meteorology, Bundesstraße 53, 20146 Hamburg, Germany.

E-mail: bader@dkrz.de changes in the ocean that feed back on the atmosphere. In atmospheric general circulation model (AGCM) experiments, Rodwell et al. (1999) and Latif et al. (2000) found an oceanic control of decadal North Atlantic sea level pressure variability in winter. Using atmospheric general circulation models Hoerling et al. (2001, 2004), Bader and Latif (2003), and Hurrell et al. (2004) recently showed that the progressive warming of the Indian Ocean (see Fig. 1) may be a principal contributor to the recent change of the North Atlantic Oscillation. This study puts forward a hypothesis of how the Indian Ocean sea surface temperature anomalies may affect the North Atlantic Oscillation. Since we are using a coupled ocean-atmosphere model in which the SSTs are interactively calculated in the Atlantic sector we are able to account for ocean-atmosphere feedbacks in this sector.

\section{Model and experiments}

The model used in this study is the Max Planck Institute (MPI) global ocean-atmosphere-sea ice model MPI-OM/ECHAM5. A detailed description of the atmosphere model ECHAM5 is given in a technical report (Roeckner et al. 2003). The ocean model is de- 


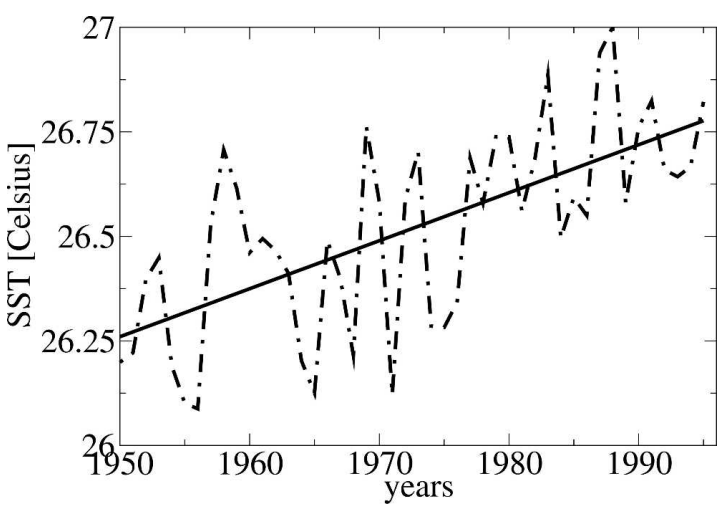

FIG. 1. Observed annual tropical Indian Ocean SST index $\left({ }^{\circ} \mathrm{C}\right)$, based on the Reynolds SSTs, averaged from $30^{\circ} \mathrm{S}$ to $30^{\circ} \mathrm{N}$ from the east coast of Africa to $120^{\circ} \mathrm{E}$. The dotted-dashed curve denotes the annual means, the solid curve the linear trend.

scribed in Marsland et al. (2003). First applications of the coupled model are studies of Latif et al. (2004) and Pohlmann et al. (2004). The atmospheric model is run at T31 $\left(\sim 3.75^{\circ} \times 3.75^{\circ}\right)$ horizontal resolution with 19 vertical levels. The ocean model, MPI-OM, is run at a horizontal resolution of $\sim 3^{\circ} \times 3^{\circ}$ with 40 vertical levels. The model does not employ flux corrections. A 200-yrlong control simulation is performed, initialized at year 140 of another control integration to eliminate the spinup. Additionally, two sensitivity experiments are performed. In these experiments the ocean temperature of the first layer in the tropical Indian Ocean (from East Africa to $\sim 120^{\circ} \mathrm{E}$ and from $\sim 30^{\circ} \mathrm{S}$ to the south coast of Asia) is prescribed using climatological SST of the control integration and a trend is superimposed. In the first 75 years, the climatological values are enhanced/reduced by $1.5 \mathrm{~K}$ in the tropical Indian Ocean. Thereafter the SST in the Indian Ocean is kept constant (Fig. 2). Please note that the trend is much stronger than the interannually produced variability in the control integration. In all ocean areas other than the tropical Indian Ocean the SST is calculated interactively.

The model simulates realistically the North Atlantic Oscillation pattern and captures the essential feature of the observed NAO, that is, the mass exchange between the high and midlatitudes (not shown).

Additionally, sensitivity experiments are performed with the atmospheric general circulation model ECHAM4.5 (Roeckner et al. 1996) run in stand-alone mode. The model forced by the observed SSTs from 1951 to 1994 simulates the observed low-frequency NAO index variations reasonably well (Latif et al. 2000). The climatological second Atmospheric Model Intercomparison Project (AMIP2) SSTs (Taylor et al. 2000) are used for the control experiment. Two sensitivity experiments are performed: In the first sensitivity

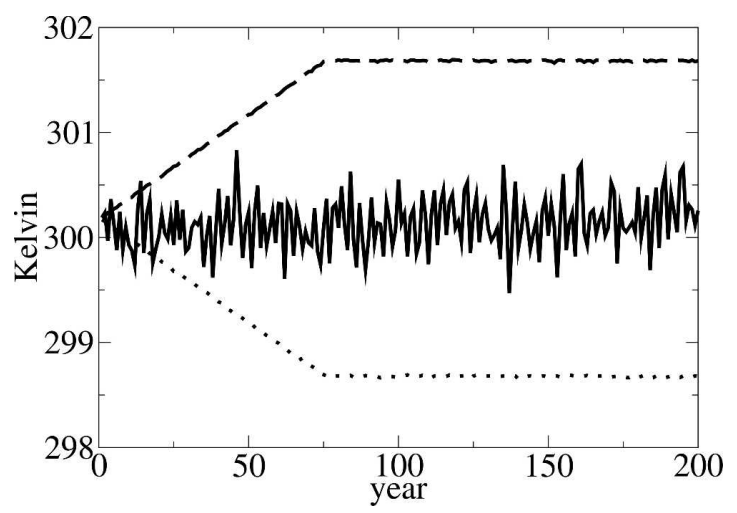

FIG. 2. Annual SSTs (K) averaged over the tropical Indian Ocean for the control integration (solid curve), for the SST sensitivity experiments "warm Indian Ocean" (dashed curve) and "cold Indian Ocean" (dotted curve).

experiment the climatological SSTs in the whole tropical Indian Ocean are reduced by $1 \mathrm{~K}$ (from East Africa to $\sim 120^{\circ} \mathrm{E}$ and from $\sim 30^{\circ} \mathrm{S}$ to the south coast of Asia). In the second sensitivity experiment the SST anomalies are restricted to the western tropical Indian Ocean (from East Africa to $\sim 80^{\circ} \mathrm{E}$ and from $\sim 30^{\circ} \mathrm{S}$ to the south coast of Asia). (The climatological AMIP2 SSTs cover the period from January 1979 to February 1996. We reduce the SSTs in the Indian Ocean to go back in time since the observed Indian Ocean SSTs show a positive trend.)

Results for the AGCM experiments are obtained from a set of 21-yr-long SST sensitivity experiments. The results are averaged over the last 19 years and only the mean December-February (DJF) response (sensitivity run minus control integration) is shown here.

\section{Results}

Figures $3 \mathrm{a}$ and $3 \mathrm{~b}$ show the mean DJF sea level pressure response for the two individual OAGCM sensitivity simulations (mean of the sensitivity experiment minus mean of the control integration; the means are computed over the whole integration length). The sea level pressure response to a warm/cold Indian Ocean shows a meridional seesaw pattern with low/high SLP anomalies north of approximately $55^{\circ} \mathrm{N}$ and high/low SLP south of this latitude. A warm Indian Ocean produces a stronger NAO (Fig. 3a) and a cold Indian Ocean a weaker NAO (Fig. 3b). To first order the response is almost linear. The response patterns are very similar to the first EOF loading pattern of the simulated winter sea level pressure of the control integration. These coupled atmosphere-ocean experiments confirm the findings that slow changes in the state of the ocean 


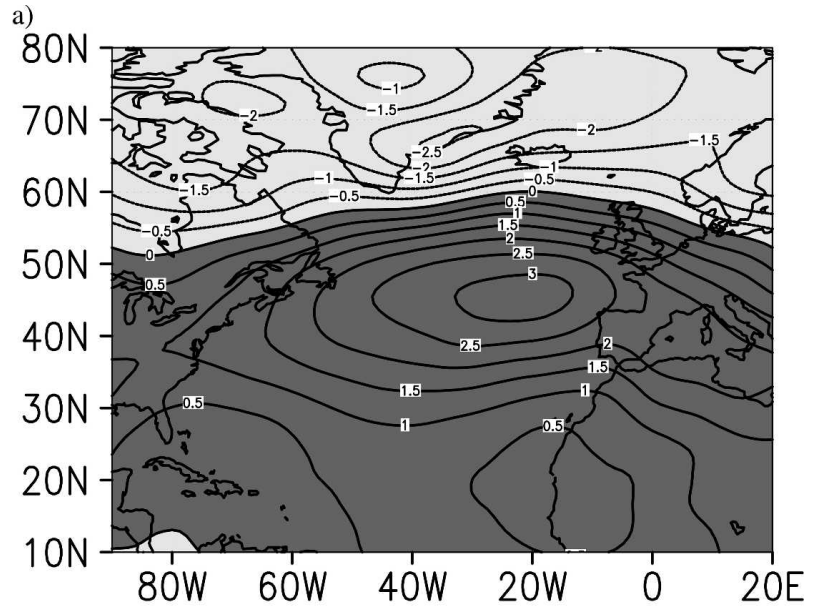

b)

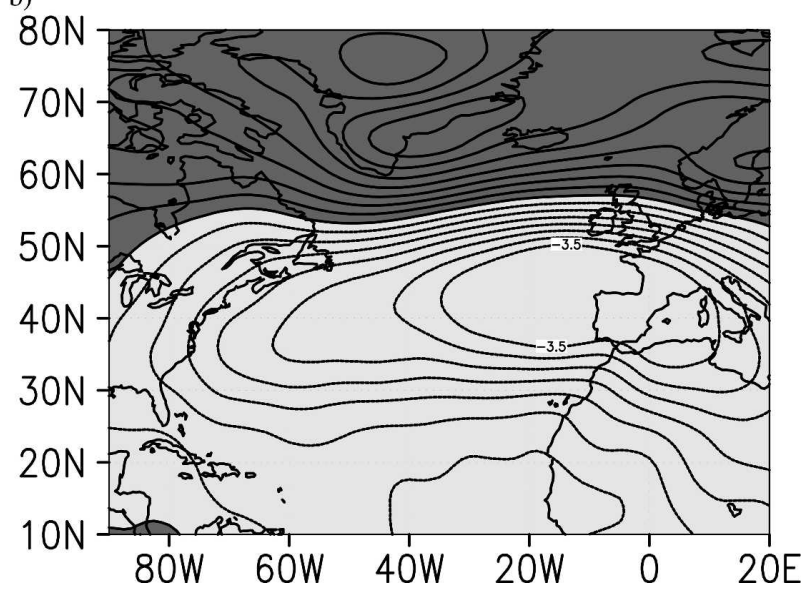

FIG. 3. Mean DJF sea level pressure anomaly $(\mathrm{hPa})$ relative to control integration for the SST sensitivity experiments (a) "warm Indian Ocean" and (b) "cold Indian Ocean."

force the NAO on longer time scales (e.g., Rodwell et al. 1999; Latif et al. 2000) and, especially, show a clear Indian Ocean impact on the NAO. This is in agreement with the findings of Hoerling et al. (2001, 2004), Bader and Latif (2003), and Hurrell et al. (2004) who analyzed AGCM experiments.
Key questions concern the mechanisms by which changes in the tropical Indian Ocean SSTs can influence the NAO. It is well established that tropical SST anomalies impact tropical rainfall and, thus, latent heating, which in turn drives changes in atmospheric circulation at higher latitudes (Hoerling et al. 2001). A prominent example is El Niño (see, e.g., Trenberth et al. 1998). How does the Indian Ocean affect the North Atlantic sector? The study by Branstator (2002) shows that disturbances in the vicinity of the mean jets, especially the South Asian jet, lead to covariability between widely separated points. He shows that the NAO is likely to include contributions from the circumglobal waveguide pattern. Based on this study we would like to show that the circumglobal teleconnection associated with the South Asian jet stream may be the link between the Indian Ocean warming and the recent trend of the NAO, which was also suggested by $\mathrm{Lu}$ et al. (2004) as a topic for future study.

First, we show that this type of circumglobal wave is simulated in our model. We begin our analysis by considering the $300-\mathrm{hPa}$ meridional wind in our control integration of the coupled model. To show covariability between points in the South Asian jet and distant regions, the correlation between the winter (DJF) 300$\mathrm{hPa}$ meridional wind averaged over the area from $25^{\circ}$ to $35^{\circ} \mathrm{N}, 55^{\circ}$ to $65^{\circ} \mathrm{E}$-indicated by the black box in Fig. 4-and the DJF meridional wind in the Northern Hemisphere in our control integration is calculated. Figure 4 reveals an anomaly pattern with alternating signs that is meridionally confined to the vicinity of the jets and consists of anomalies that are zonally oriented, extending over the whole Northern Hemisphere. This circumglobal covariability is confirmed by the first EOF of the winter $300-\mathrm{hPa}$ meridional wind in the control run (Fig. 5). Our findings are in agreement with the more comprehensive analysis of Branstator (2002) who found the largest teleconnectivity in the jet stream waveguide both in simulations and observations. In the following we test whether there is any connection be-

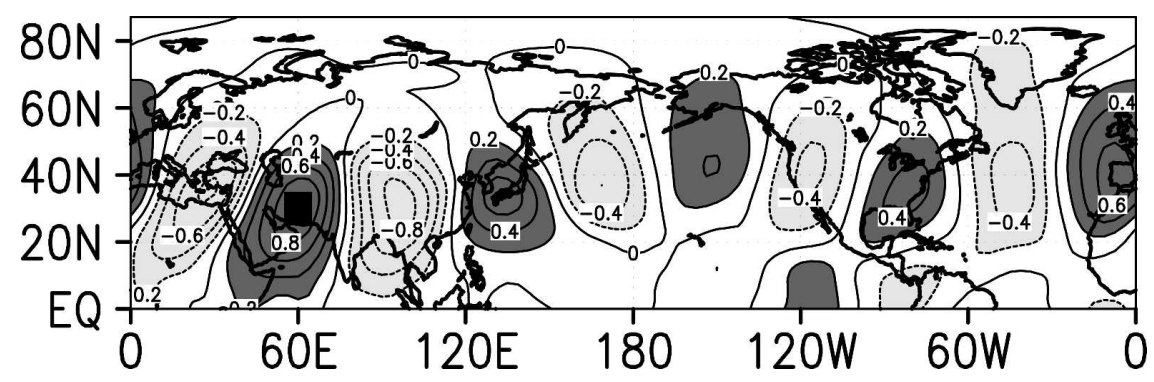

FIG. 4. Correlation of winter (DJF) 300-hPa meridional wind averaged over the black box and winter $300-\mathrm{hPa}$ meridional wind in the Northern Hemisphere. 


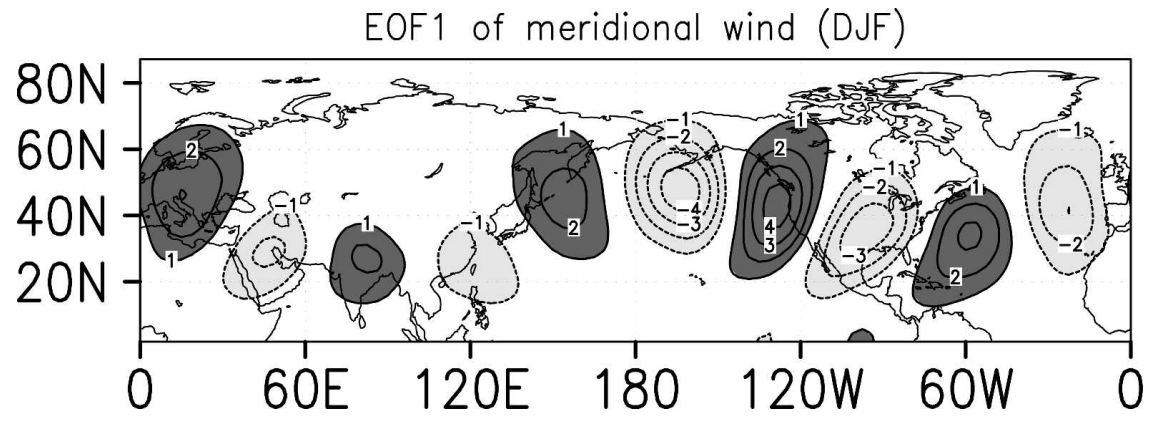

FIG. 5. The leading EOF of Northern Hemisphere 300-hPa winter (DJF) meridional wind $\left(\mathrm{m} \mathrm{s}^{-1}\right.$ per std dev).

tween the NAO and this circumglobal pattern in our control simulation. Figure 6 shows the correlation between the NAO index-the first principal component (PC1) of winter sea level pressure in the Atlantic sector (computed over the domain from $1.856^{\circ}$ to $87.159^{\circ} \mathrm{N}$, $78.75^{\circ} \mathrm{W}$ to $18.75^{\circ} \mathrm{E}$ ) — and the winter $300-\mathrm{hPa}$ meridional wind. To show the similarity in the correlation and in the circumglobal pattern in Fig. 5 the crosses in Fig. 6 mark the centers of the ten lobes of the circumglobal pattern. In agreement with Branstator (2002) we find that the NAO is likely to have contributions from the circumglobal pattern.

Next, we investigate whether the circumglobal pattern in Fig. 5 is associated with zonal wind anomalies. Figure 7 shows the correlation coefficients between the circumglobal pattern index-PC1 of the winter $300-\mathrm{hPa}$ meridional wind-and the zonal wind in the control integration. We find a wavelike pattern spanning the whole Northern Hemisphere and that the circumglobal pattern is associated with zonal wind anomalies in the area of the South Asian jet (Fig. 7). The pattern in the South Asian region (between the equator and $45^{\circ} \mathrm{N}$ and eastward from $0^{\circ}$ to $120^{\circ} \mathrm{E}$ ) is characterized by positive correlation coefficients in the western part of the South Asian jet and negative ones over the northwestern In- dian Ocean. Additionally, we show the relationship between the NAO and the zonal wind anomalies. Figure 8 shows the correlation between the NAO index-the PC1 of winter sea level pressure in the Atlantic sector (computed over the domain $1.856^{\circ}-87.159^{\circ} \mathrm{N}, 78.75^{\circ} \mathrm{W}-$ $18.75^{\circ} \mathrm{E}$ ) - and the winter $300-\mathrm{hPa}$ zonal wind in the control simulation. We find typical NAO wind anomalies in the Atlantic sector and a similar correlation pattern in the South Asian jet region as that in Fig. 7. On the one hand, Figs. 7 and 8 show that the circumglobal wave pattern has structural similarities to the NAO over the North Atlantic sector; on the other hand, there are some differences between these two phenomena. This suggests that the circumglobal wave pattern may be contributing to changes in the NAO but that other mechanisms also play an important role.

We have shown that changes in the NAO are associated with changes in the South Asian jet via the circumglobal pattern. An amplified (reduced) NAO is connected with a stronger (weaker) South Asian jet, especially in the area around $60^{\circ} \mathrm{E}$. Hence, we shall test next if similar changes of the South Asian jet as those in Figs. 7 and 8 are produced in our sensitivity experiments.

Figures $9 \mathrm{a}$ and $9 \mathrm{~b}$ show the simulated winter zonal

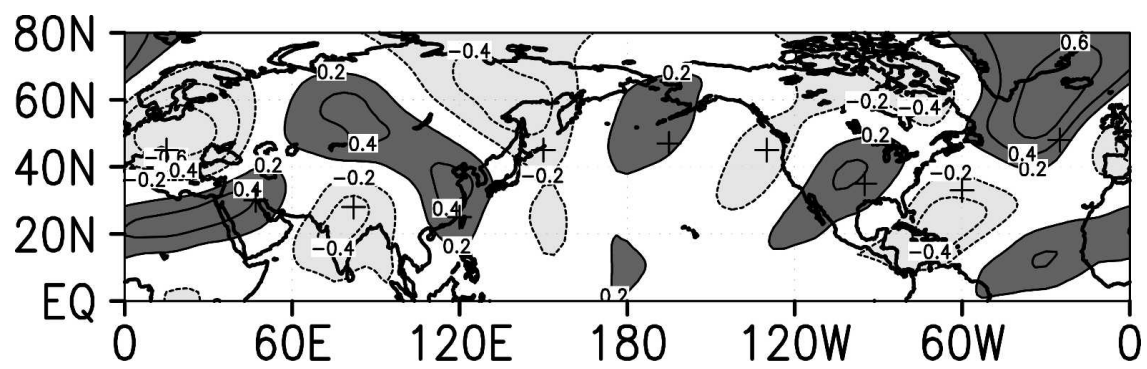

FIG. 6. Correlation of winter (DJF) 300-hPa meridional wind with the first principal component of winter (DJF) sea level pressure over the North Atlantic sector (NAO index) in the control integration. The crosses mark the centers of the ten lobes in the EOF1 plot of the meridional wind in Fig. 5. 


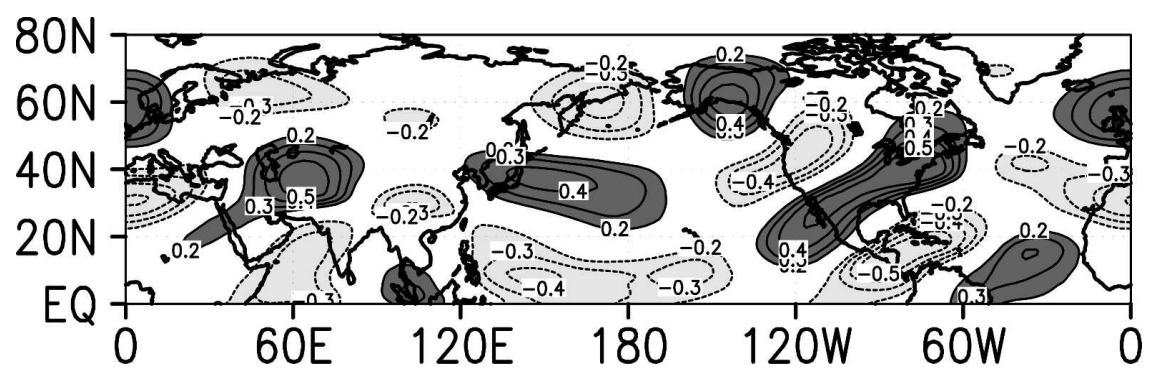

FIG. 7. As in Fig. 6 but for meridional wind in the control integration.

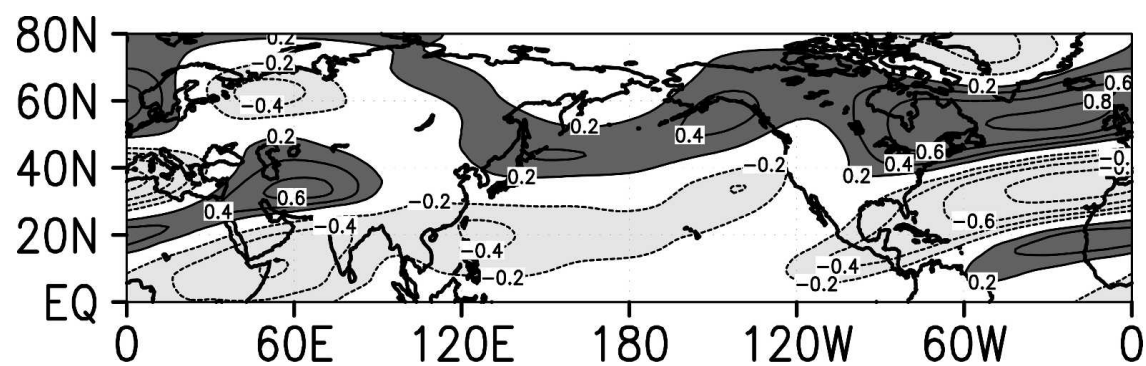

FIG. 8. As in Fig. 6 but for sea level pressure over the North Atlantic sector (NAO index) in the control integration.

a)

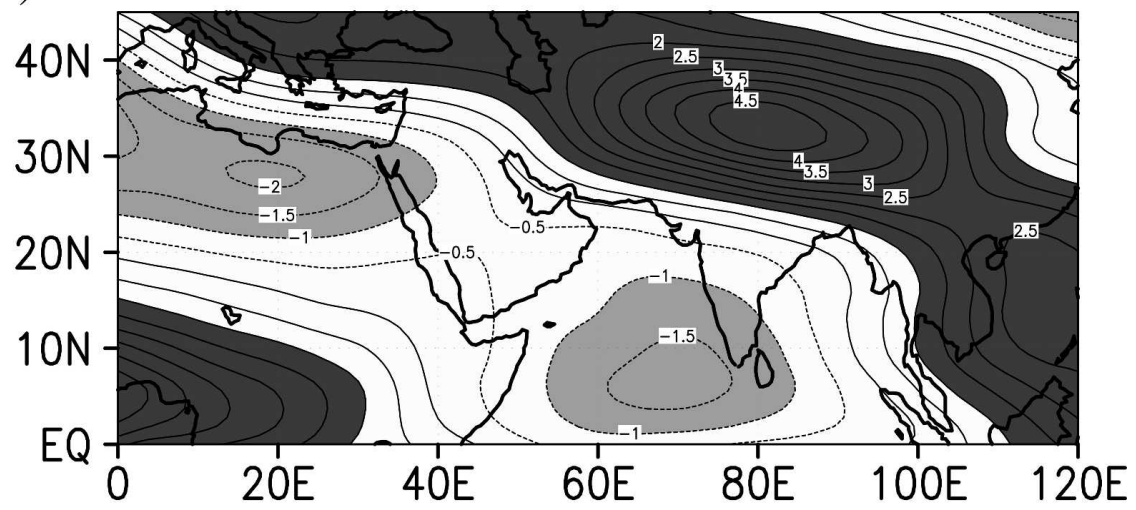

b)

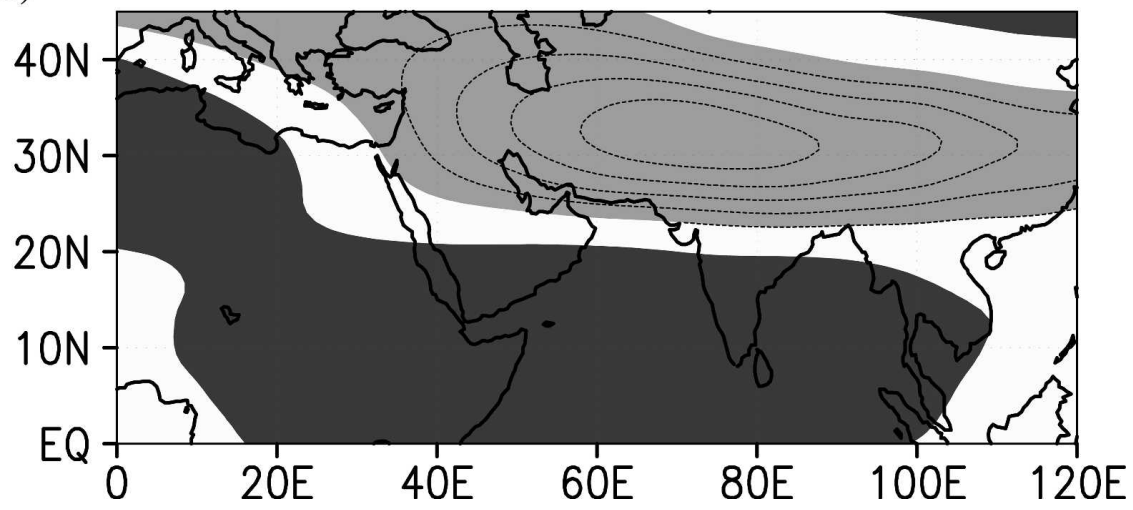

FIG. 9. Mean simulated winter (DJF) 300-hPa zonal wind anomaly relative to control integration for the SST sensitivity experiments (a) "warm Indian Ocean" and (b) "cold Indian Ocean." Units: $\mathrm{m} \mathrm{s}^{-1}$. 
wind response of the warm and cold Indian Ocean experiments. The warm Indian Ocean experiment (strong NAO) is characterized by positive anomalies in the area of the Asian jet and negative anomalies over the northwestern Indian Ocean (Fig. 9a) and vice versa for the cold experiment (weak NAO, Fig. 9b). The cause for the intensity change of the south Asian jet could be Rossby waves excited from the equatorial heating anomalies. The precipitation response especially near the south equatorial Indian Ocean is characterized by an increase (reduction) in rainfall due to higher (lower) SSTs (not shown). Figure 10a shows the time series of the simulated South Asian jet index-zonal wind in 300 $\mathrm{hPa}$ averaged from $25^{\circ}$ to $35^{\circ} \mathrm{N}, 40^{\circ}$ to $80^{\circ} \mathrm{E}$-for the individual OAGCM simulations. Additionally, the NAO indices for the individual experiments are shown in Fig. 10b. The NAO index here is defined by the difference in box-averaged normalized DJF sea level

(a)

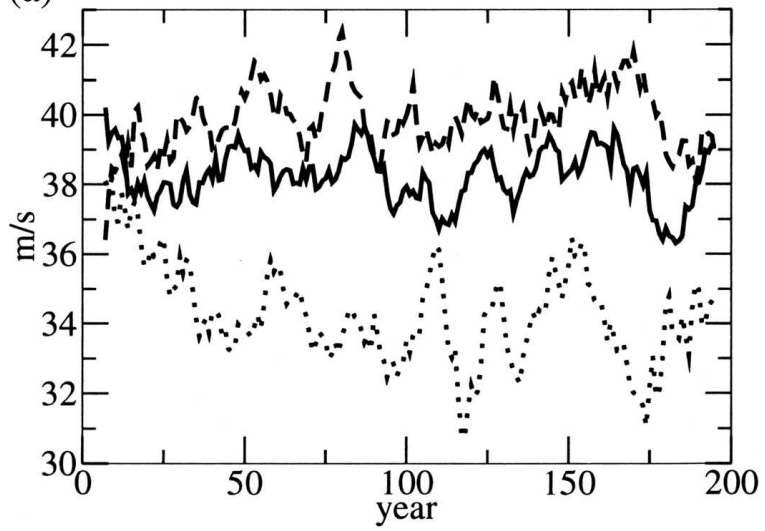

(b)

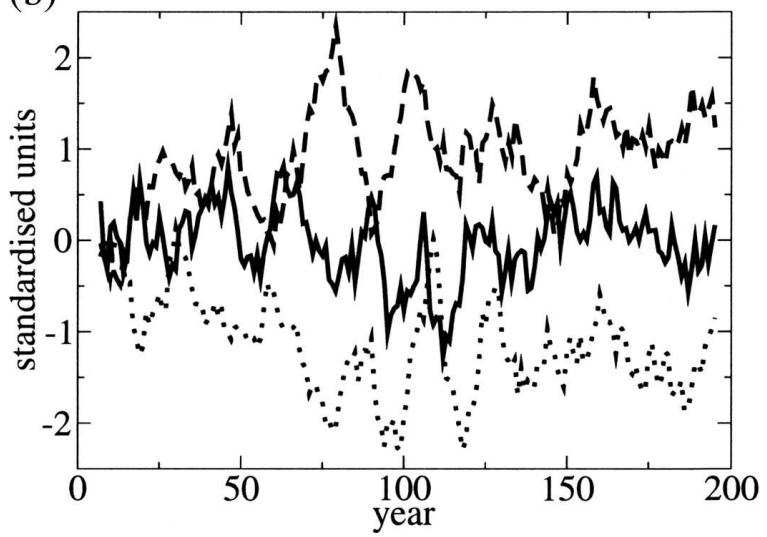

FIG. 10. Simulated 11-yr running mean time series of the winter (DJF) (a) zonal wind anomaly index in the South Asian jet region and (b) NAO index relative to the mean of the control integration for the control integration (black curve) and for the SSTsensitivity experiments "warm Indian Ocean" (dashed curve) and "cold Indian Ocean" (dotted curve). pressure between a southern and a northern box in the North Atlantic sector. The northern box is defined from $60^{\circ}$ to $80^{\circ} \mathrm{N}, 60^{\circ} \mathrm{W}$ to $0^{\circ}$ and the southern box from $30^{\circ}$ to $50^{\circ} \mathrm{N}, 60^{\circ} \mathrm{W}$ to $0^{\circ}$. Figure $10 \mathrm{~b}$ shows the three NAO indices relative to the mean of the control integration. Figures $10 \mathrm{a}$ and $10 \mathrm{~b}$ show clearly that NAO trends are connected with South Asian jet trends. The response of the jet appears to be somewhat stronger in the cold Indian Ocean experiment. The observed warming trend in the Indian Ocean (Fig. 1) should also be associated with a trend in the observed South Asian jet. Figure 11 shows the time series of the observed South Asian jet DJF zonal wind in $300 \mathrm{hPa}$ averaged from $25^{\circ}$ to $35^{\circ} \mathrm{N}, 40^{\circ}$ to $80^{\circ} \mathrm{E}$, based on the National Centers for Environmental Prediction (NCEP) reanalysis data. There is a clear trend toward a stronger South Asian jet, which confirms our findings. Figure 12 shows the observed (NCEP reanalysis data) winter $300-\mathrm{hPa}$ meridional wind anomaly between the mean of the years (1982-93) minus (1949-60). The circumglobal pattern shows up in Fig. 12. This suggests that also, in reality, the circumglobal pattern contributed to the recent NAO trend. However, other dynamical mechanisms may also contribute to the NAO trend. In particular there is a distinct zonal wave-3 disturbance in high latitudes.

Figure 8 shows the strongest correlation between NAO and winter zonal $300-\mathrm{hPa}$ wind in the South Asian jet region between approximately $55^{\circ}$ and $65^{\circ} \mathrm{E}$. It is now tested whether the west Indian Ocean may be the principal contributor for the change in the western South Asian jet and, therefore, in the NAO. This is tested by two simple AGCM experiments. In the first

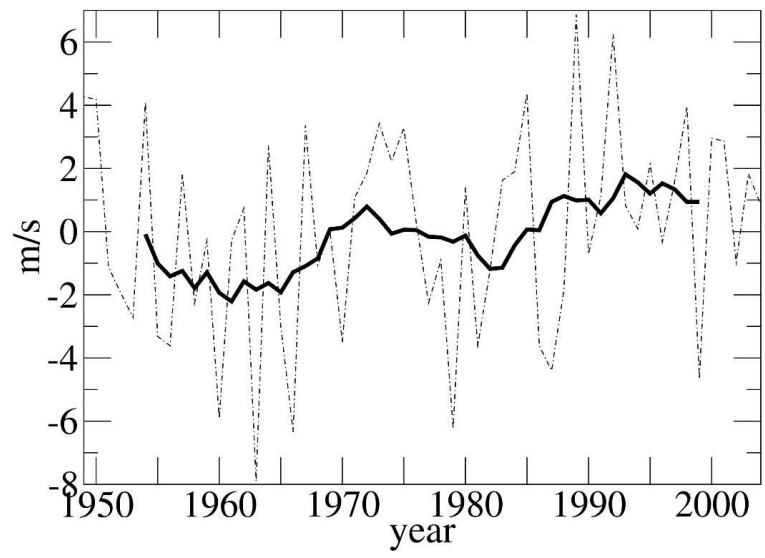

FIG. 11. Observed winter (DJF) zonal wind anomaly index (see text for details) in the South Asian jet region, based on the NCEP reanalysis data. The dotted-dashed curve denotes the seasonal means; the thick solid black curve denotes the 11-yr running mean. 


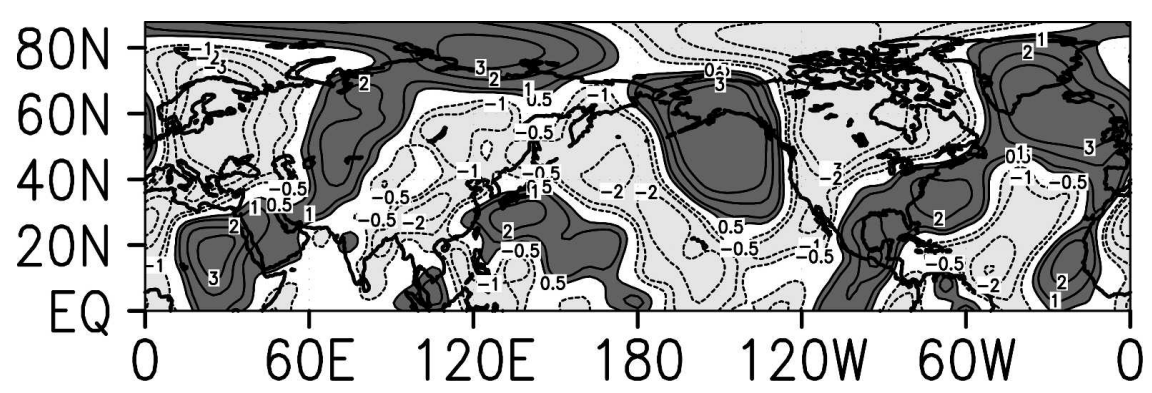

FIG. 12. Observed meridional $300-\mathrm{hPa}$ winter (DJF) wind anomaly $\left(\mathrm{m} \mathrm{s}^{-1}\right)$ between the mean of the years 1982-93 minus 1949-60, based on the NCEP reanalysis data.

experiment, the whole Indian Ocean climatological SSTs are reduced by $1 \mathrm{~K}$. In the second sensitivity experiment with the AGCM, the SST anomalies are restricted to the western tropical Indian Ocean. Please note that the SSTs are reduced in the Indian Ocean in both experiments. Figure 13 shows the sea level pres-

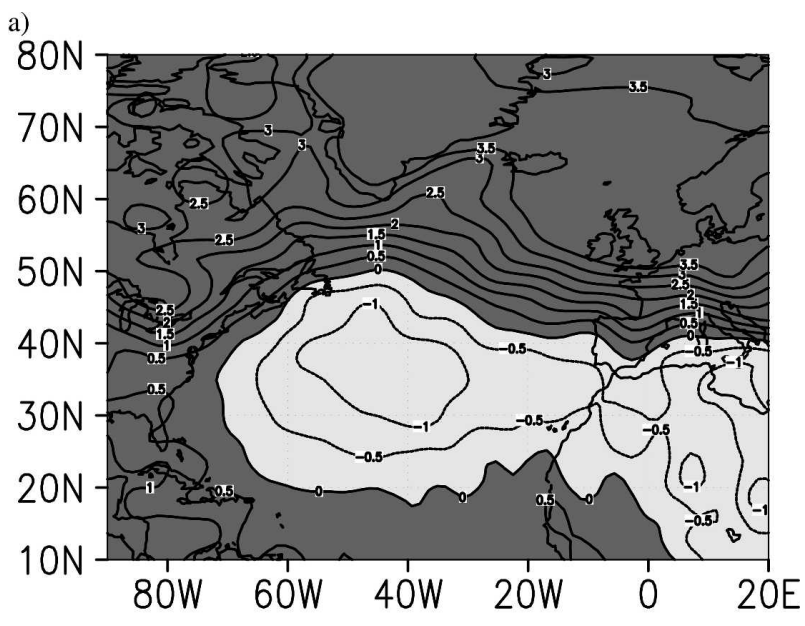

b)

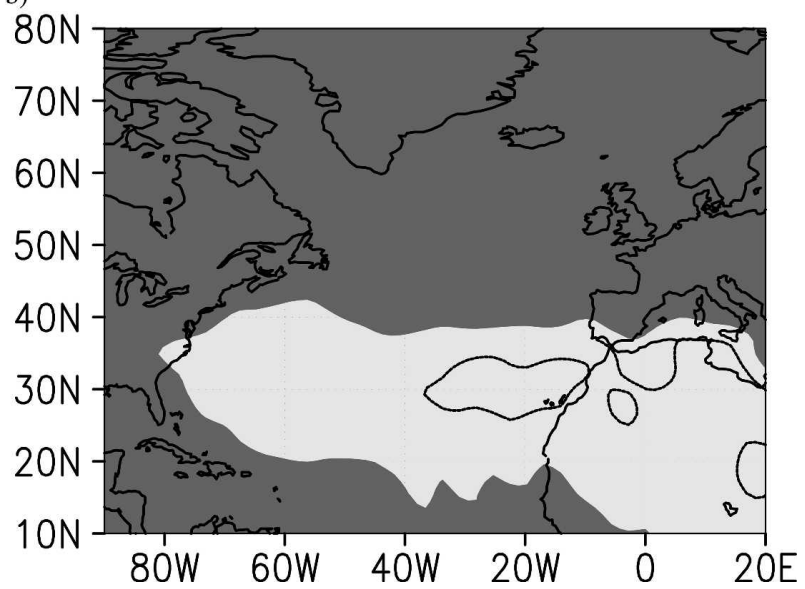

FIG. 13. Mean DJF sea level pressure anomaly (hPa) relative to control integration for the SST sensitivity experiment (a) "Indian Ocean minus $1 \mathrm{~K}$ " and the (b) "western Indian Ocean minus $1 \mathrm{~K}$ " experiment. sure response for the two individual experiments. Both experiments produce a NAO-like sea level pressure response. A weakening of both the Icelandic low and the Azorian high is simulated. A two-tailed $t$ test indicates that the results are significant at the $95 \%$ confidence level in both experiments, at least in the centers of action. Apparently, west Indian Ocean SST anomalies are sufficient to force the NAO. Figure 14 shows the mean DJF 300-hPa meridional wind response for the "western Indian Ocean minus $1 \mathrm{~K}$ " experiment (sensitivity experiment minus control integration). It reveals a wavy response in the Northern Hemisphere closely resembling the circumglobal pattern. A clear reduction in the western South Asian jet is simulated (not shown). These atmospheric experiments confirm that Indian Ocean SST anomalies force changes in the South Asian jet. The South Asian jet produces a variability pattern that composes the whole Northern Hemisphere. This circumglobal pattern then can lead to changes in the NAO.

\section{Conclusions}

By analyzing model simulations we found that the South Asian jet can act as a waveguide with circumglobal teleconnection in the Northern Hemisphere. The meridional wind pattern, associated with this circumglobal teleconnection, is connected with the North Atlantic Oscillation. A warming/cooling in the Indian Ocean, especially in the western Indian Ocean, produces anomalies in the South Asian jet. The waveguiding effect of the South Asian jet carries the perturbation into the North Atlantic sector and leads to a NAOlike response.

The observed recent positive trend in the NAO has likely contributions from the observed warming in the Indian Ocean. Our analysis-confirmed by the observed trend in the western South Asian jet and the anomaly pattern of the $300-\mathrm{hPa}$ winter meridional wind-indicates that the change of the NAO may be via the circumglobal pattern. 


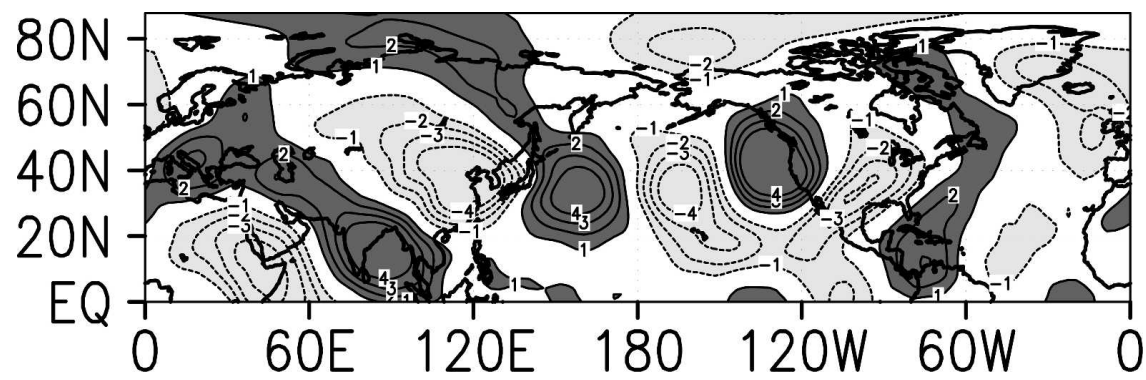

FIG. 14. Meridional 300-hPa winter (DJF) wind response for the "western Indian Ocean minus $1 \mathrm{~K}$ " experiment; units: $\mathrm{m} \mathrm{s}^{-1}$.

Acknowledgments. The authors thank Dr. Johann Jungclaus for help with the coupled model, Daniela Matei for her useful comments, and Katja Lohmann for the IDL help. This work was supported by the Federal German Ministry of Education and Research (BMBF) under Grants 01 LW 0301A (Glowa) and 01 LD 0030 (DEKLIM), and the Ministry of Science and Research (MWF) of the state of Northrhine-Westfalia under Grant 223-212 00 200. The model runs were performed at the German Climate Computing Center (DKRZ).

\section{REFERENCES}

Bader, J., and M. Latif, 2003: The impact of decadal-scale Indian Ocean sea surface temperature anomalies on Sahelian rainfall and the North Atlantic Oscillation. Geophys. Res. Lett., 30, 2169, doi:10.1029/2003GL018426.

Branstator, G., 2002: Circumglobal teleconnections, the jet stream waveguide, and the North Atlantic Oscillation. J. Climate, 15, 1893-1910.

Cayan, D. R., 1992: Latent and sensible heat flux anomalies over the northern oceans: The connection to monthly atmospheric circulation. J. Climate, 5, 354-369.

Hoerling, M. P., J. W. Hurrell, and T. Y. Xu, 2001: Tropical origins for recent North Atlantic climate change. Science, 292, 90-92.

, T. Xu, G. T. Bates, and A. Phillips, 2004: Twentieth century North Atlantic climate change. Part II: Understanding the effect of Indian Ocean warming. Climate Dyn., 23, 391-405.

Hurrell, J. W., 1995: Decadal trends in the North Atlantic Oscillation: Regional temperatures and precipitation. Science, 269, 676-679.

—, Y. Kushnir, G. Ottersen, and M. Visbeck, Eds., 2003: The North Atlantic Oscillation: Climatic Significance and Environmental Impact. Amer. Geophys. Union, 279 pp.

_, M. P. Hoerling, A. Phillips, and T. Xu, 2004: Twentieth century North Atlantic climate change. Part I: Assessing determinism. Climate Dyn., 23, 371-389.

James, I. N., and P. M. James, 1989: Ultra-low-frequency variability in a simple atmospheric model. Nature, 342, 53-55.

Latif, M., K. Arpe, and E. Roeckner, 2000: Oceanic control of North Atlantic sea level pressure variability in winter. Geophys. Res. Lett., 27, 727-730.

— , and Coauthors, 2004: Reconstructing, monitoring, and predicting multidecadal-scale changes in the North Atlantic thermohaline circulation with sea surface temperature. J. Climate, 17, 1605-1614.

Lu, J., R. J. Greatbatch, and A. Peterson, 2004: Trend in Northern Hemisphere winter atmospheric circulation during the last half of the twentieth century. J. Climate, 17, 3745-3760.

Marsland, S. J., H. Haak, J. H. Jungclaus, M. Latif, and F. Röske, 2003: The Max-Planck-Institute global ocean/sea ice model with orthogonal curvilinear coordinates. Ocean Modell., 5, 91-127.

Pohlmann, H., M. Botzet, M. Latif, A. Roesch, M. Wild, and P. Tschuck, 2004: Estimating the decadal predictability of a coupled OAGCM. J. Climate, 17, 4463-4472.

Rodwell, M. J., D. P. Rowell, and C. K. Folland, 1999: Oceanic forcing of the wintertime North Atlantic Oscillation and European climate. Nature, 398, 320-323.

Roeckner, E., and Coauthors, 1996: The atmospheric general circulation model ECHAM-4: Model description and simulation of present-day climate. MPI Rep. 218, $90 \mathrm{pp}$.

- , and Coauthors, 2003: The atmospheric general circulation model ECHAM 5. MPI Rep. 349, 127 pp.

Saravanan, R., and J. C. McWilliams, 1997: Stochasticity and spatial resonance in interdecadal climate fluctuations. J. Climate, 10, 2299-2320.

Taylor, K. E., D. Williamson, and F. Zwiers, 2000: The sea surface temperature and sea ice concentration boundary conditions for AMIP II simulations. PCMDI Rep. 60, 24 pp.

Trenberth, K. E., G. W. Branstator, D. Karoly, A. Kumar, N. C. Lau, and C. Ropelewski, 1998: Progress during TOGA in understanding and modeling global teleconnections associated with tropical sea surface temperatures. J. Geophys. Res., 103 (C7), 14 291-14 324 